\title{
A CASE REPORT ON CONGENITAL LOBAR EMPHYSEMA
}

\author{
KARTHIKA UNNIKRISHNAN, ANILA KN*
}

${ }^{1}$ Department of Pharmacy Practice, Amrita School of Pharmacy, Kochi, Amrita Vishwa Vidyapeetham, Amrita University, India. Email: anilakn@aims.amrita.edu

Received: 01 February 2017, Revised and Accepted: 17 April 2017

\section{ABSTRACT}

Congenital lobar emphysema (CLE) disorder is an uncommon respiratory issue in which air can enter the lungs yet cannot escape, bringing about over inflation (hyperinflation) of the projections of the lung with an incidence 1 per 20,000-30,000 per birth. It is frequently recognized in babies or youthful newborn children; however, a few cases do not get to be distinctly evident until adulthood. This issue might be sufficiently serious to bring about related heart issues. We report a case of a 1-month-old female infant who showed the signs and symptoms of this disease, but responded well to her treatment and was discharged in a stable state.

Keywords: Congenital lobar emphysema, Overinflation, Newborns.

(c) 2017 The Authors. Published by Innovare Academic Sciences Pvt Ltd. This is an open access article under the CC BY license (http://creativecommons. org/licenses/by/4. 0/) DOI: http://dx.doi.org/10.22159/ajpcr.2017.v10i7.17418

\section{INTRODUCTION}

Nelson RLin 1932 first described congenital lobar emphysema (CLE) [1]. In this, air enters lungs, cannot escape, and causing over inflation of lung lobes. Often detected in newborns or young infants but some presented at late childhood [2]. Synonyms for CLE is congenital lobar overinflation and infantile lobar emphysema [3]. CLE is a rare condition causing over inflation of lung lobes, compress ipsilateral, and contralateral normal lungs; hence, neonatal acute respiratory distress is often seen. Etiology of the condition is not well understood [3,4]. Heart problems $(15 \%$ cases) are seen associated with this condition. Diagnosis includes clinical examination, routine chest X-rays, and CT scan. The main treatment includes surgery. Infants usually show dyspnea, tachypnea, retraction, wheezing, cyanosis, coughing, and increased intrathoracic pressure. The condition is potentially reversible $[4,5]$.

\section{CASE REPORT}

A 1-month-old female infant born by caesarean section (for a mother with gestational diabetes mellitus) with a birth weight of $3.260 \mathrm{~kg}$ was admitted with complaints of fast breathing and difficulty in feeding. On clinical examination, the patient was active, afebrile with respiratory rate $-40 /$ minutes, and $\mathrm{SpO}_{2}-9 \%$ on room air. The patient was tachypneic with suprasternal subcostal chest retraction. She had a history of respiratory distress and was in NICU for 6 days. She later had a history of lower respiratory infection and breathing difficulty twice. Computerized tomography (CT) chest with contrast was suggestive of the left upper lobe CLE with suspicious right middle lobe involvement. The left perfusion scan showed 39\% uptake on the left side. She underwent left thoracotomy and upper lobectomy. Post-operatively recovery was uneventful. She was started on oral feeds. Chest X-ray showed partially expanded left lower lobe. Her tachypnea resolved later and was feeding well. Implantable cardioverter defibrillator) was removed on the $5^{\text {th }}$ post-operative day. At discharge, she is stable, afebrile, and feeding well.

CT scan of chest with IV contrast had features suggestive of CLE of the left upper lobe. There was suspicious hyperinflation of the right middle lobe.

Lung perfusion scan showed significantly reduced tracer distribution in right apical, anterior, posterior segments, left apicoposterior, superior, anterior, and small part of lateral basal segments. However, homogeneous normal Macro aggregated albumin (MAA) tracer distribution in bilateral lower lobes and all other lung segments. The percentage MAA uptake in left: Right lung segments were 39:61\%.

Echo showed patent foramen ovale left to right shunt. Operative findings include erythematous left upper lobe, with lingual and lobe spared. The patient was checked for air leak and discharged with syrup Taxim-0 (Cefixime), Folvite (folic acid) drops, syrup uprise (cholecalciferol) and Paracetamol drops.

\section{DISCUSSION}

The prevalence of CLE is 1 in 20,000-1 in 30,000 and incidence is 1 in 70,000-1 in 90,000. Usually, unilateral and upper left lobe most affected (42\%), but the right middle (35\%) also affected. Bilateral involvement found exceptionally rare [6]. Here, the patient had left upper lobe involvement with suspicious right middle lobe involvement. The patient was tachypneic and showed suprasternal subcostal chest retraction and had respiratory distress and breathing difficulty which are the characteristic features of CLE. Symptoms usually start from a few days after birth to 6 months [7]. Here, it developed within 1 month. Proper clinical examinations, chest X-rays, and CT help rule out the other conditions. Here, also a clinical examination, chest X-ray, CT chest with IV contrast, lung perfusion scan, etc., were done. CLE patients presenting later in life shows recurrent chest infections [8]. Correcting the underlying cardiac defect helps in relieving lobar emphysema [9].

\section{CONCLUSION}

Late childhood CLE at first time pose a diagnostic challenge to physicians. Recently for CLE of mild symptoms, endoscopic parenchymal sparing resection was performed. Diagnosis to be made early and an operative mortality rate of $3-7 \%$ is reported while performing surgery. There is more scope for research in this area of early detection and its management.

\section{REFERENCES}

1. Cataneo DC, Rodrigues OR, Hasimoto EN, Schmidt Jr AF, Cataneo AJ. Congenital lobar emphysema: 30-year case series in two university hospitals. J Bras Pneumol 2013;39:418-26.

2. Available from: http//www.rare diseases.org/rare-diseases/emphysemacongenital-lobar/.

3. Nath MP, Gupta S, Kumar A, Chakrabarty A. Congenital lobar 
emphysema in neonates: Anaesthetic challenges. Indian J Anaesth 2011;55(3):280-3

4. Tempe DK, Virmani S, Javetkar S, Banerjee A, Puri SK, Datt V. Congenital lobar emphysema: Pitfalls and management. Ann Card Anaesth 2010;13:53-8.

5. Varma VK, Thakur V, Kumar A, Bhardwaj G. Congenital lobar emphysema: Anaesthetic considerations. Egypt J Cardiothorac Anaesth 2014;8(2):88-90.

6. Abushahin AM, Tuffaha AS, Khalil NK, Ismeal AM. Bilateral congenital lobar emphysema: A rare cause of respiratory distress in
Infancy. Ann Thorac Med 2012;7(4):250-2

7. Mahaldar DC, Kumar S, Balamurugan K, Raghuram AR, Krishnan R, Kannan. Congenital lobar emphysema. Indian J Anaesth 2009;53(4):482-5.

8. Santra A, Dutta P, Manjhi R, Pothal S. Congenital lobar emphysema presenting at late childhood: A rare case report. Lung India 2014;31(3);302-4

9. Moideen I, Nair SG, Cherian A, Rao SG. Congenital lobar emphysema associated with congenital heart disease. J Cardiothorac Vasc Anaesth 2006;20(2):239-41. 